\title{
Spatial, Dietary and Temporal Niche Dimensions in Ecological Segregation of Two Sympatric, Congeneric Marsupial Species
}

\author{
Nilton C. Cáceres ${ }^{1, *}$ and Arielli F. Machado ${ }^{2}$ \\ ${ }^{1}$ Laboratory of Ecology and Biogeography, Department of Biology, Universidade Federal de Santa Maria, Camobi, \\ Santa Maria, RS, 97.110-970, Brazil \\ ${ }^{2}$ Programa de Pós-Graduação em Ecologia, INPA, Campus V8, Av. Rodrigo Otávio, 35, Coroado, Manaus, AM, \\ 69.080-971, Brazil
}

\begin{abstract}
Didelphis aurita and D. albiventris are widely distributed in South America, with a range of sympatry in the limit of their distribution, particularly in Araucaria mixed ombrophilous forest in the southern Atlantic Forest. We investigated the spatial, feeding, and time use between these morphologically similar species in a remnant of Araucaria forest in southern Brazil for one year. We tested the hypothesis that these species when in sympatry segregate each other in space use, diet, and/or activity time. We expect that they segregate between each other primarily in the dimension of space use, as occurs for Australian congeneric marsupials. We used a mark-capture-release protocol for obtaining data. We analysed the spatial segregation by measuring the distance of captures in relation to the remnant centre, stream and edges. There were significant differences in the use of space, as adult females of $D$. aurita used mainly the remnant interior and stream sides, and D. albiventris females its edges or open areas. The consumption of feeding resources, particularly fruits, was different mainly between females and during the breeding season. However, there was no difference in the activity time between species. We believe that the territorial behaviour of $D$. aurita females had a crucial role in this spatial segregation with $D$. albiventris females, leading to a diet differentiation, particularly for fruits which were highly available inside the remnant. Interspecific competition between females is thought to be the main reason maintaining $D$. albiventris females far from the richest parts of the remnant. The mechanism behind this ecological segregation is discussed, and an ecological niche shift when both species are in sympatry is suggested, rather than the ghost of competition past.
\end{abstract}

Keywords: Brazilian Araucaria mixed forest, Coexistence, Didelphis, Ecological shift, Feeding habits, Forest edges, Ghost of competition past, Interspecific competition, Territorial behaviour.

\section{INTRODUCTION}

Sympatric, closely related species tend to differ ecologically, leading to different adaptive strategies or to the use of different niche dimensions, such as spatial, temporal and feeding niches (Schoener, 1974). When this does not occur, the species will compete for the limited resources by competition itself, such as by direct interference, or by competition by exploitation, in which they indirectly dispute the resource which is limited (Lotka, 1932; Wootton, 1994). Thus, interspecific competition leads, through time, to the segregation of an ecological niche, and when there is a coexistence of closely related species it is believed that they will compete for a limited resource affecting the stability of the community (Lotka, 1932; Pianka, 1978). On the other hand, the ecological segregation between two species can be derived from past competition, and species will behave accordingly by separating themselves in the most ecological dimensions, but not precisely by the actual competition

*Address correspondence to this author at the Departamento de Biologia, Universidade Federal de Santa Maria, Bairro Camobi, Santa Maria, RS, 97.110-970, Brazil. Tel/Fax: 0055 32208465;

E-mail: niltoncaceres@gmail.com
(Connell, 1980; Jones and Barmuta, 2000; Krebs, 1999). Studies investigating niche segregation among closely related species are important for understanding the mechanisms of coexistence (Catzeflis et al., 1997, Dickman, 1986; Jones and Barmuta, 2000).

The genus Didelphis Linnaeus, 1758 (Order Didelphimorphia) is common in the Neotropics, being widely distributed and present in primary and disturbed vegetations (Emmons and Feer, 1997). In eastern South America, there are two related species, Didelphis aurita Wied-Neuwied, 1826, which is associated with the Atlantic Forest occurring on the Atlantic coast, and $D$. albiventris Lund, 1840, which occurs mostly in more open vegetation, such as the Cerrado (savannah-like) and the Pampas (grassland-like vegetation) ecoregions (Emmons and Feer, 1997). They are molecularly different for $5.73 \%$ of the sequences of the mitochondrial cytochrome $b$ gene (K2P), which is thought to be a low level of species differentiation (Costa et al., 2003; Costa and Patton, 2006), implying that species could be similar in both ecology and behaviour. Although $D$. albiventris and $D$. aurita are morphologically similar, they can be differentiated by ear coloration (Emmons and Feer, 1997). However, both are found to occur in sympatry in mixed ombrophilous forest (Araucaria forest) 
of southern Brazil (Cáceres et al., 2007), an upland Atlantic Forest formation where the Brazilian pine Araucaria angustifolia (Bertol.) Kuntze is common. Sympatry of the two species occurs also in a narrow north-south zone between the Atlantic forest and Cerrado ecoregions (Cerqueira, 1985; Emmons and Feer, 1997; Varejão and Valle, 1982). This sympatry remains poorly understood because it is not known exactly how the two species behave in micro-sympatry in terms of resource use. In the Araucaria forest, when not in sympatry, it is expected that $D$. aurita occurs mostly in forested sites (Cáceres et al., 2007; Davis, 1945; Gentile and Fernandez, 1999; Pires et al., 2002), and D. albiventris in open grassland-scrubland areas as well as forested sites (Cáceres, 2002; Sanches et al., 2012; Talamoni and Dias, 1999).

The breeding season of both $D$. aurita and D. albiventris in the study region begins in July and extends until January or April according to the species (Cáceres, 2000; Cáceres and Monteiro-Filho, 1998), but the duration is latitudedependent in the species range (Rademaker and Cerqueira, 2006). During this time, reproductive females of $D$. aurita are territorial, segregating spatially, possibly to ensure food resources (Cáceres, 2003). Didelphis aurita females can also be found preferentially near water courses when dwelling in a forest remnant (Cáceres and Monteiro-Filho, 2001), showing a tendency to consume food resources found in such wetter sites (Cáceres, 2003; Mendel et al., 2008). Didelphis aurita males increase their movement rate, reaching different forest fragments during the reproductive season to search for oestrous females (Cáceres and Monteiro-Filho, 1998), hence showing a more unpredictable pattern of movement (Mendel et al., 2008). These characteristics are also expected to occur in the congeneric D. albiventris (Cáceres, 2000). During the breeding season of $D$. aurita, and probably of $D$. albiventris, there are many seasonally ecological and behavioural changes in each of the sexes, such as the extended lactation time and associated parental care for females (Cáceres, 2000, 2003; Gentile et al., 2004; Mendel et al., 2008).

Didelphis aurita and D. albiventris are primarily generalists with regard to food habits. They are known to be opportunists and consume various sources of food, from fruits to insects and small vertebrates, in the Atlantic Forest (Cáceres, 2002, 2003; Cáceres and Monteiro-Filho, 2001; Cáceres et al., 1999; Carvalho et al., 2005). Information available for these two species living in sympatry is scarce, but indicates that differentiation in consuming more food items is related to their primary habitat. It appears that $D$. aurita can eat more forest food items than D. albiventris when in sympatry. In fact, evidence for this is the consumption of more fruits from the forest interior by $D$. aurita than D. albiventris; for instance, this latter species can eat more fruits from ruderal and grassland plants (Cáceres and Monteiro-Filho, 2001, 2007; Cáceres, 2002).

Regarding activity, D. aurita and D. albiventris are nocturnal (Emmons and Feer, 1997). For D. aurita, this species decreases its time of activity throughout the night, but activity can continue all night to dawn (Cáceres and Monteiro-Filho, 2001). It is expected that D. albiventris follows the same activity pattern of $D$. aurita, and mainly in sympatry, but no evidence has been reported.
Studies dealing with the mechanisms of coexistence among sympatric marsupials are plentiful in Australia (e.g. Dickman, 1986; Jones, 1998; Jones and Barmuta, 2000; Kaufmann, 1974), but they are rarer in South America, where there are no studies on the ecological dynamics of sympatry involving $D$. aurita and $D$. albiventris, and fewer still for any Neotropical congeneric, sympatric marsupial species regarding ecological segregation (but see Catzeflis et al., 1997). Therefore, it is important to address the resource exploitation and associated behaviour of these two species in a vegetation physiognomy that allows the sympatry of both species, such as the Araucaria forest, in the upper parts of the Atlantic Forest biome (IBGE, 1992). Studies on ecological niche segregation between congeneric species are important in order to better understand the dynamic of coexistence of two closely related species, by identifying which niche dimension plays an important role in ecological segregation. In Australia, small carnivorous marsupials segregate more spatially than temporally when coexisting sympatrically (Dickman, 1986; Jones and Barmuta, 2000).

Thus, we tested the hypothesis that when the species $D$. aurita and $D$. albiventris are living in sympatry, they differ in at least one dimension of the ecological niche as a mechanism of coexistence, since they are species of very similar form and size (Emmons and Feer, 1997) and closely related (Costa and Patton, 2006). We believe that the spatial dimension will be the key for the coexistence of both species sympatrically, since using the space differently will lead to alternative diets for such species, implying possible interference in the competition between species. Bearing in mind that the studied remnant is small (i.e., space is heterogeneous and limited), if a species uses its interior more, the other will use the edges and outside more, leading to possibly different diets. Therefore, we do not expect a difference only for diet and not for space, since this will imply exploitative competition between both species, which is more difficult to implement based on the knowledge of marsupial coexistence and behaviour (Dickman, 1986; Ginger et al., 2003; Jones and Barmuta, 2000). We believe that the territorial behaviour exhibited by $D$. aurita females (Cáceres, 2003) is key for this scenario, as this will primarily favour segregation of females of the two species in a spatial manner. We expect that $D$. aurita will select the central parts of the area, as well portions close to the stream; edges are expected to be less important in this possible spatial segregation because of the irregular form of the remnant, since the edges can be very close to the centre or to the stream headwater. We also believe that the active time will not be as important for the coexistence of both species, because opossums are extremely nocturnal (Emmons and Feer, 1997), which restricts the time required to adjust to the active time.

\section{MATERIALS AND METHODS}

\section{Study Area}

The study area is located in the municipality of Curitiba, Paraná state $\left(25^{\circ} 25^{\prime} \mathrm{S} ; 4^{\circ} 18^{\prime} \mathrm{W}\right)$ and belongs to the Cooperativa Paranaense de Energia Elétrica (COPEL) (Fig. 1). The forest remnant has an area of five hectares with an irregular shape that is covered by mixed ombrophilus forest 


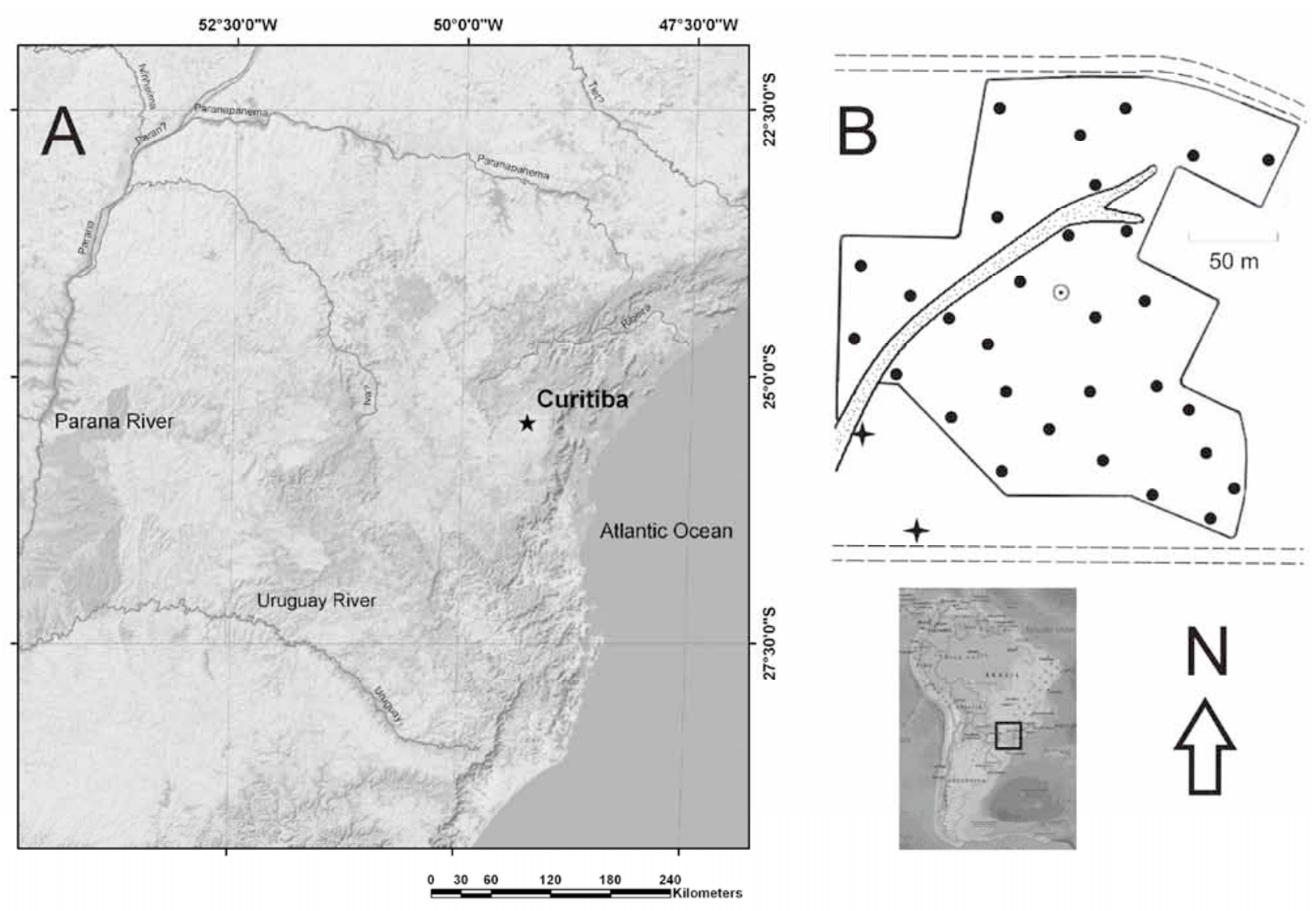

Fig. (1). Localisation of the study area in Southern Brazil (A) and its configuration $(\mathbf{B})$ in a periurban region of Curitiba city, in Paraná state. Black circles are live traps inside the fragment and stars are outside it, in grasslands. Dotted area is a creek with a stream headwater in the remnant, dashed lines around the remnant are paved roads, and the white circle is the remnant centre. Source for map: National Geographic Society.

(Araucaria forest). Araucaria angustifolia is a common tree in the region. The area is mainly undisturbed, but there is some local disturbance and a considerable edge effect at distances from 5 to 20 metres from the sharp edge (seen by visual assessment of vegetation structure). There is a stream of clean water within the area, which receives polluted water immediately after leaving the remnant area. The stream averages $4 \mathrm{~m}$ in width and is inserted in a valley with a depth of about 5 to $6 \mathrm{~m}$. The area is located in the urban limit of the city of Curitiba, and is surrounded by portions of ruderal and open areas, gardens, houses and paved streets. Barigüi Park, which is a green area of 140 hectares with mixed ombrophilus forest, is close to the study area. The average annual temperature in the region is $16.5^{\circ} \mathrm{C}$, relative air humidity is generally high (averaging $81.5 \%$ ), and the annual rainfall is 1,100-1,600 $\mathrm{mm}$ (Maack, 1981). The dry season is not well marked; April and August are the driest months and January and February the wettest (Cáceres and MonteiroFilho, 2007).

Curitiba is at an altitude of 940 metres and is located in the Brazilian Southern Plateau, where the typical vegetation is mixed ombrophilous forest. This vegetation almost entirely occupies the plateau at an altitude above 500 metres in southern Brazil, but is currently uncharacterised, and is restricted mostly to small forest remnants. In addition to the Araucaria angustifolia, such a formation is typically composed of Ocotea pulchella and Ilex paraguariensis, accompanied by Cryptocarya aschersoniana and Nectandra megapotamica. Many species of the families Myrtaceae, Lauraceae and Solanaceae are also found and they are also common in dense ombrophilous forests (IBGE, 1992).

\section{Data Collection}

Opossum species were differentiated by cheeking their ear colours (Emmons and Feer, 1997); this is valid even for those with a young age class 3 (Eisenberg and Redford, 1999; Tyndale-Biscoe and Machenzie, 1976), which was the minimum class trapped here. Captures of animals were performed once a week from February 1995 to January 1996, using 32 traps arranged uniformly in the remnant area, and baited with banana, cod liver oil and peanut butter. Wire traps (national model similar to Tomahawk) with a size of $40 \times 20 \times 20 \mathrm{~cm}$ were installed in fixed points of the study area, and were located approximately $38 \mathrm{~m}$ from each other, arranged in the interior, edges and some open areas adjacent to the remnant (Fig. 1). These cage traps were capable of capturing even large-sized opossums (up to $2.120 \mathrm{~kg}$ ). Captured opossums were differentiated by sex and age (based on dentition: number of teeth erupted; TyndaleBiscoe and Mackenzie, 1976), marked with ear holes for the identification of individuals, and released after manipulation.

Faeces were collected from the trap floors when the animal was released and the items were analysed and identified in a laboratory to record the diet of each species 
(see Cáceres, 2002, for more details). Usually, all opossums left faeces when trapped. The frequency of occurrence of each identifiable food item (e.g. a given species of fruit, order of Arthropoda, or class of vertebrate) was determined by counting how many times each food item appeared in all faecal samples of an individual; i.e., only the presence and absence of each item was taken into account per faecal sample, and the presences were summed for a given individual and divided by the total faecal sample for that individual.

For examining the activity time of species throughout the night, nine one-night surveys were carried out from April 1995 to January 1996 (except June). These nocturnal rounds started at 18:00 $\mathrm{h}$ and finished at 08:00 $\mathrm{h}$ in each incursion. Night was divided into four periods, each with an interval of $3.5 \mathrm{~h}$, and rounds to check the traps were performed in each of these intervals. In each period, captured individuals of both species of opossum were identified by their ear markings and were released immediately. With this procedure, first captures of each individual in each $3.5 \mathrm{~h}$ period during the night occurred, and some recaptures of the same individual were performed, but in different traps. In this case, only the first capture of each individual during each period was used for activity time, and only the first one during the entire night was used for spatial and dietary analyses previously described.

\section{Mapping Capture Stations}

To analyse the space use between the species, we used the protocol of capture and recapture of individuals and an illustrated map of the remnant and its adjacencies (Fig. 1). Each trap position was noted on a map of the study area, extracted from an aerial photograph, with a known scale (1: 2000); each trap position was located easily in the study area map, since we know the precise geography of the relief and vegetation particularities. Each position of each capture regarding different individuals of both opossum species in the trap grid was recorded. Based on this map, we measured the distance of each trap in relation to the remnant centre, stream and edges with the aid of a digital calliper (accuracy of $0.01 \mathrm{~mm}$ ). Subsequently, each distance was converted into metres for analysis. We believe that this method has some potential errors, but is thought to be equal to or more efficient than using a GPS device, when considering the errors incurred when tracking a position via satellite, mainly due to obstruction by the forest cover. Given the small scale of the study area, we opted for this method, and estimated the error to be less than $5 \mathrm{~m}$.

The centre of the remnant area was obtained from a central point of the circle circumscribed to its extreme borders, using the same map of the study area. The position of the stream, as well as the edges, was easily obtained from the map cited above.

We have chosen these methods to evaluate the distance of each individual capture regarding (1) the centre of the remnant and (2) the nearest portion of the stream in its interior, due to the known patterns of space used by $D$. aurita, whose individuals select sites within the remnant and mainly near the stream (Cáceres, 2003). If individuals of $D$. aurita select these sites within the remnant, it is plausible that a measure of distance from its centre or from the stream will be useful to understand the patterns of use of space by $D$. aurita and also those of $D$. albiventris, if the species segregate spatially from each other, as we hypothesised before. However, given the irregular form of the remnant, with the edges sometimes close to the stream headwater (Fig. 1), the distance of each capture (3) to the nearest remnant edge was also computed for both species. All captures of a given individual were used for the measurements of distances to the remnant centre, stream, and edges.

\section{Data Analyses}

To test whether individuals of the two species used the remnant area randomly, or if they spatially moved away in relation to the remnant centre, stream, or edges, resulting in a segregated pattern, we used the t test in the Bioestat software version 5.0 (Ayres et al., 2007). We chose this test because of its simplicity and ease of use when comparing data between two species. For this, we first averaged the captures for each individual, and then we used the mean distance in the $\mathrm{t}$ tests (Murtaugh, 2007). When the assumptions to use parametric tests were not met (e.g. homoscedasticity), we opted to use the non-parametric Mann-Whitney test because in a few cases assumptions were difficult to meet even with data transformation. All p-values here have one-tail probability as we tested whether the capture distances for $D$. albiventris were longer than the distances for D. aurita (Zar, 1984), which has shown an affinity to the interior and stream and to avoid edges more than D. albiventris, as previously hypothesised.

We have performed some tests regarding age, sex, breeding season, and combinations, to explore these different datasets for the spatial data. These tests involved 1) all individuals, 2) adults only 3) adult females, 4) adult males, 5) adult females during the breeding season, and 6) adult males during the breeding season. The non-breeding season was not assessed because of the lack of individuals for analyses. We considered the period from July to January as the breeding season and from February to June as the nonbreeding season (Cáceres, 2003).

Concerning the analysis of diet, the differences in the consumption of feeding resources between species were assessed by randomisation tests (one-way Randomisation Test Comparing Groups of Sampling Units), similar to the multiple analysis of variance (MANOVA) (Pillar and Orlóci, 1996) by using Bray-Curtis as a measure of dissimilarity among the sample units (different individuals) and food items as response variables. We tested five different datasets, one at a time for each analysis: 1) all individuals, 2) females, 3) males, 4) breeding season, and 5) non-reproductive season. For these analyses, the relative frequencies of occurrence of feeding items were counted for each individual of both species. These tests involving diet were run in the software Multiv 2.4 (Pillar, 2005).

In addition, the level of feeding overlap among the species was also analysed by calculating the Simplified Morisita Index $(\mathrm{CH})$ by using proportions of a given resource per individual (Krebs, 1999). This index calculates the degree of overlap of resources between pairs of species, which ranges from zero (when there is no overlap of resources consumed) to 1.0 (when there is a total overlap of resources). We also tested the same five datasets mentioned 


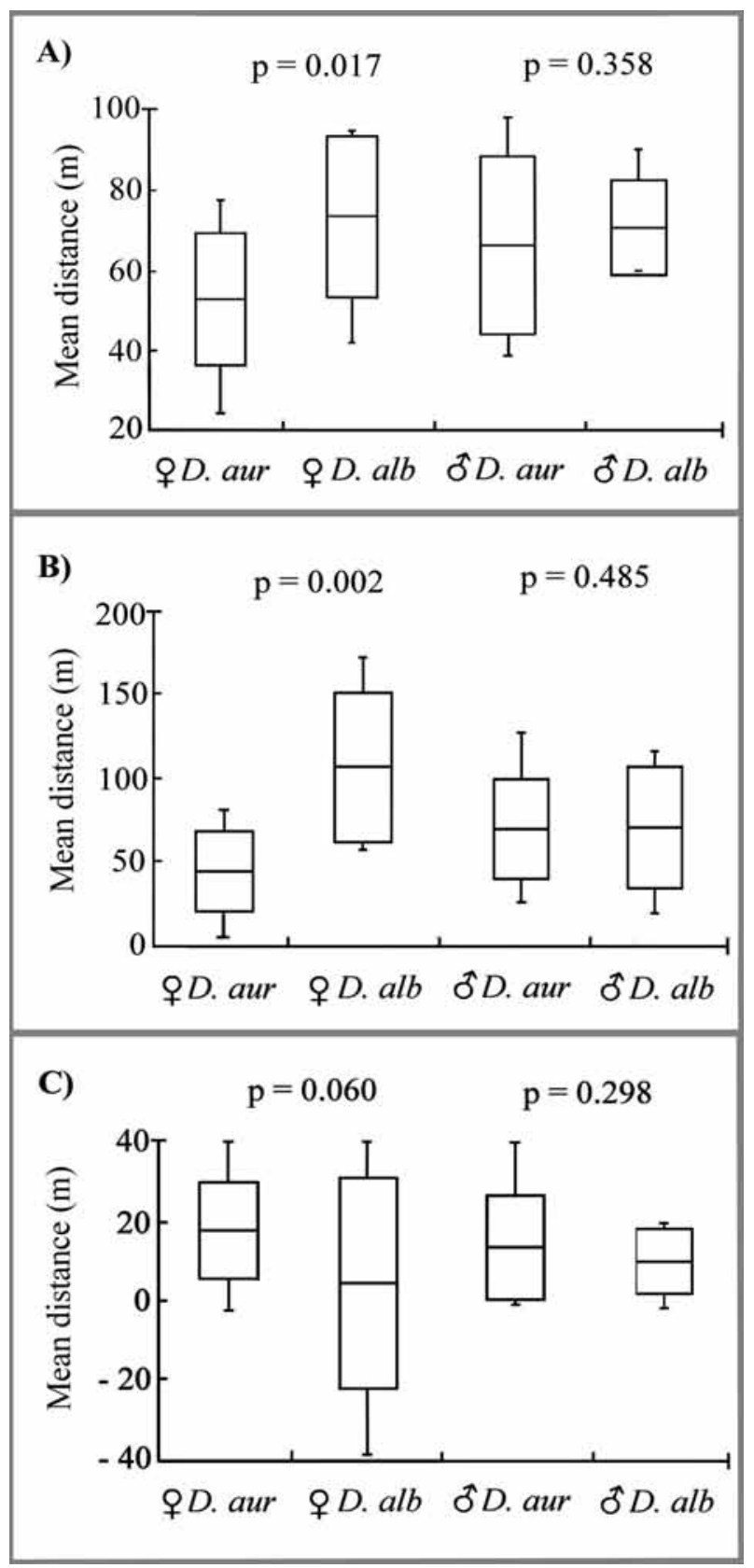

Fig. (2). Average capture distances from the remnant centre (A), stream (B), and edges (C) for adult females and males of Didelphis aurita and $D$. albiventris. Horizontal bars are means, boxes are standard deviations, and vertical bars are maximum and minimum amplitudes of the data. P-values are from one-tail t-tests (A, B) and Mann-Whitney test (C) comparing each sex between species. Negative distances in $\mathrm{C}$ mean captures outside the remnant (grassland).

above in this analysis, one at a time, as follows: 1) all individuals, 2) females, 3) males, 4) breeding season, and 5) non-breeding season.

For the analysis of nocturnal activity, the data were divided into four classes of time (18:00 to $21: 29 \mathrm{~h} ; 21: 30$ to 00:59 h; 1:00 to 04:29 h; 04:30 to 08:00 h). Then, captures of both species in each time class (without considering recaptures) were counted by class. Later, the KolmogorovSmirnov test was used to test for significant differences in the frequency of occurrence of individuals from both species in the different time intervals. Different datasets were used: all individuals, adults, adult females, and adult females during the breeding season, for which data were available. This test was run using Bioestat software version 5.0 (Ayres et al., 2007).

\section{Results}

In general, there was a complete spatial segregation between adult females of each species, with the general absence of $D$. albiventris females in the remnant interior, coupled with the major presence of $D$. aurita females in such interior and close to the stream. Males of both species did not segregate spatially, overlapping among each other, as well as young with adults. Edges were not found to be important in this segregation. Results on diet corroborated the results on space use, with the same trends seen, such as females segregating more when considering the consumption of fruits. However, males also tended to segregate with regard to diet, except for fruits. Activity time was similar for both species during the night.

\section{Use of Space}

In total, 253 captures were made during the entire sampling, with 192 captures of $D$. aurita (171 female and 21 male captures) and 61 of $D$. albiventris (30 female and 31 male captures). Captures represented 18 individuals of $D$. aurita, including 10 females and eight males, and 20 individuals of $D$. albiventris, with 13 females and seven males.

\section{Captures Regarding the Remnant Centre}

For use of space considering all individuals including young, there was no difference for distances of captures between species when considering the central area of the remnant $(\mathrm{t}=-1.24$, d.f. $=1,36, \mathrm{P}=0.112)$. Considering only adult individuals of both species, this test revealed a significant difference for captures of $D$. aurita close to the remnant centre in comparison to $D$. albiventris $(\mathrm{t}=-1.94$, d.f. $=1,29, \mathrm{P}=0.031$ ) (Fig. 2A).

The $\mathrm{t}$ test also confirmed the hypothesis of spatial differentiation by considering only adult females $(\mathrm{t}=-2.32$, d.f. $=1,16, \mathrm{P}=0.017$ ) (Fig. 3). However, the same pattern was not observed for adult males, showing that males of both species overlap spatially in the study area $(t=-0.37$, d.f. $=1$, $11, \mathrm{P}=0.358$ ) (Fig. 4). Therefore, capture distances from the remnant centre were longer for $D$. albiventris females than for those of $D$. aurita females (Table 1). This same pattern did not appear for males of the species (Fig. 2A).

The t test also revealed the differential use of space only during the breeding season for adult females, with $D$. aurita females having short distances from the remnant centre than D. albiventris females $(\mathrm{t}=-2.01$, d.f. $=1,13, \mathrm{P}=0.033)$. Again, adult males did not differ from each other in the use of space during the breeding season $(\mathrm{t}=-1.03$, d.f. $=1,10, \mathrm{P}$ $=0.163)$. The $\mathrm{t}$ tests for the non-breeding season of both sexes were not performed because the number of samples was not sufficient in each case. Therefore, with regard to the 


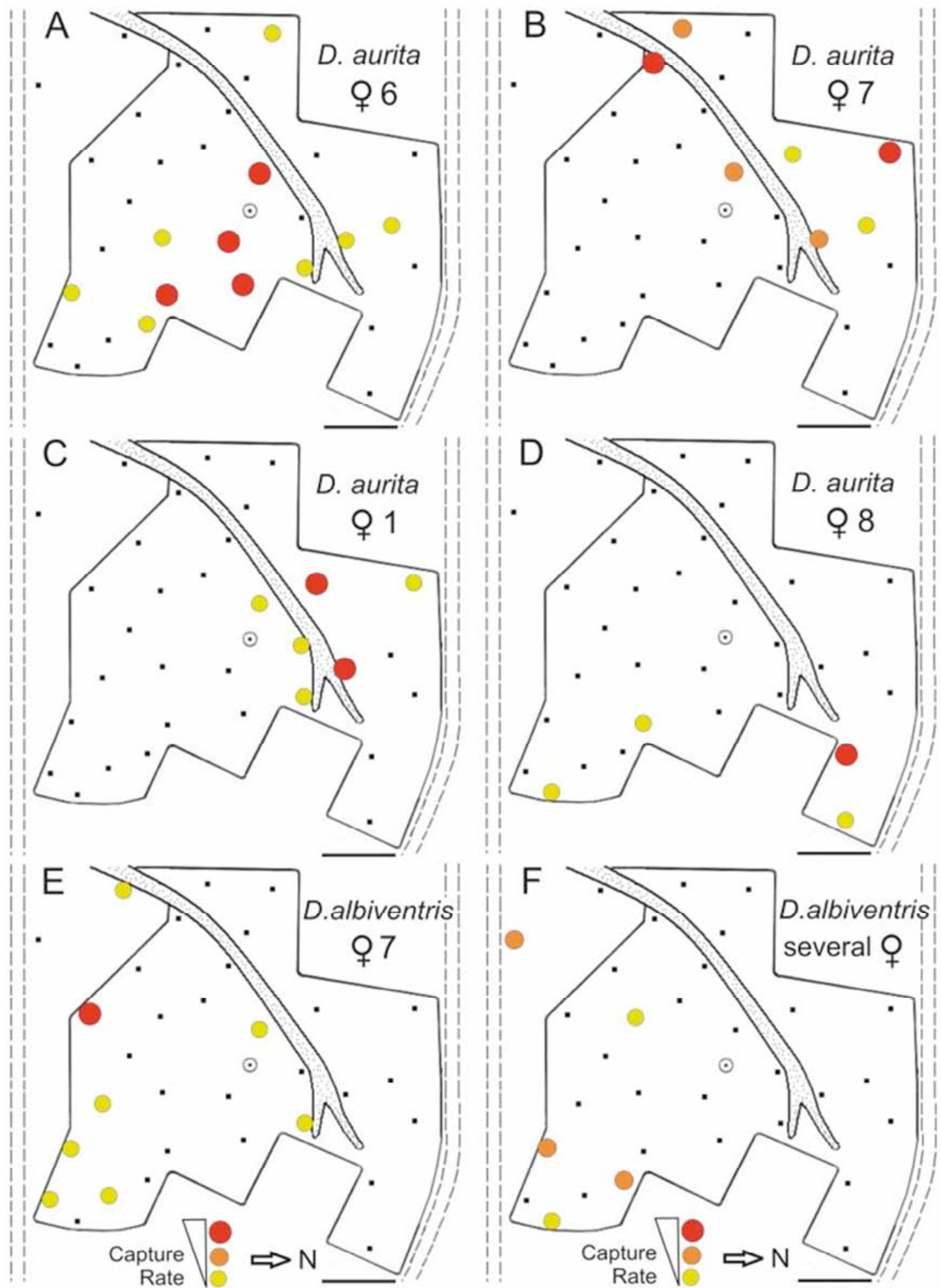

Fig. (3). Capture rates of the more frequent adult females of two sympatric species of Didelphis during the breeding season (July-January) in an Atlantic Forest remnant of southern Brazil. A, B, C and D show capture rates of females numbers 1, 6, 7 and 8 of D. aurita, with 5, 16, 21 and 5 captures, respectively. $\mathrm{E}$ and $\mathrm{F}$ are capture rates of female 7 and several $D$. albiventris females $(\mathrm{n}=7$ individuals), with 9 and 8 captures, respectively. Large and red points refer to traps with more captures ( $>75 \%$ quartile), intermediate-sized and orange circles refer to traps with intermediate level of captures, and small and yellow circles refer to traps with less captures $(<25 \%$ quartile) of one individual (except in F). In F, each small and yellow circle refers to a unique individual of $D$. albiventris and intermediate orange circles refer to two different individuals captured in the same trap position. Large dots are non-used live traps, the dotted area is a creek with a stream headwater in the remnant, dashed lines around it are paved roads, the white circle is the remnant centre, and the scale line that covers the entire lower right corner of the remnant measures $53 \mathrm{~m}$. 


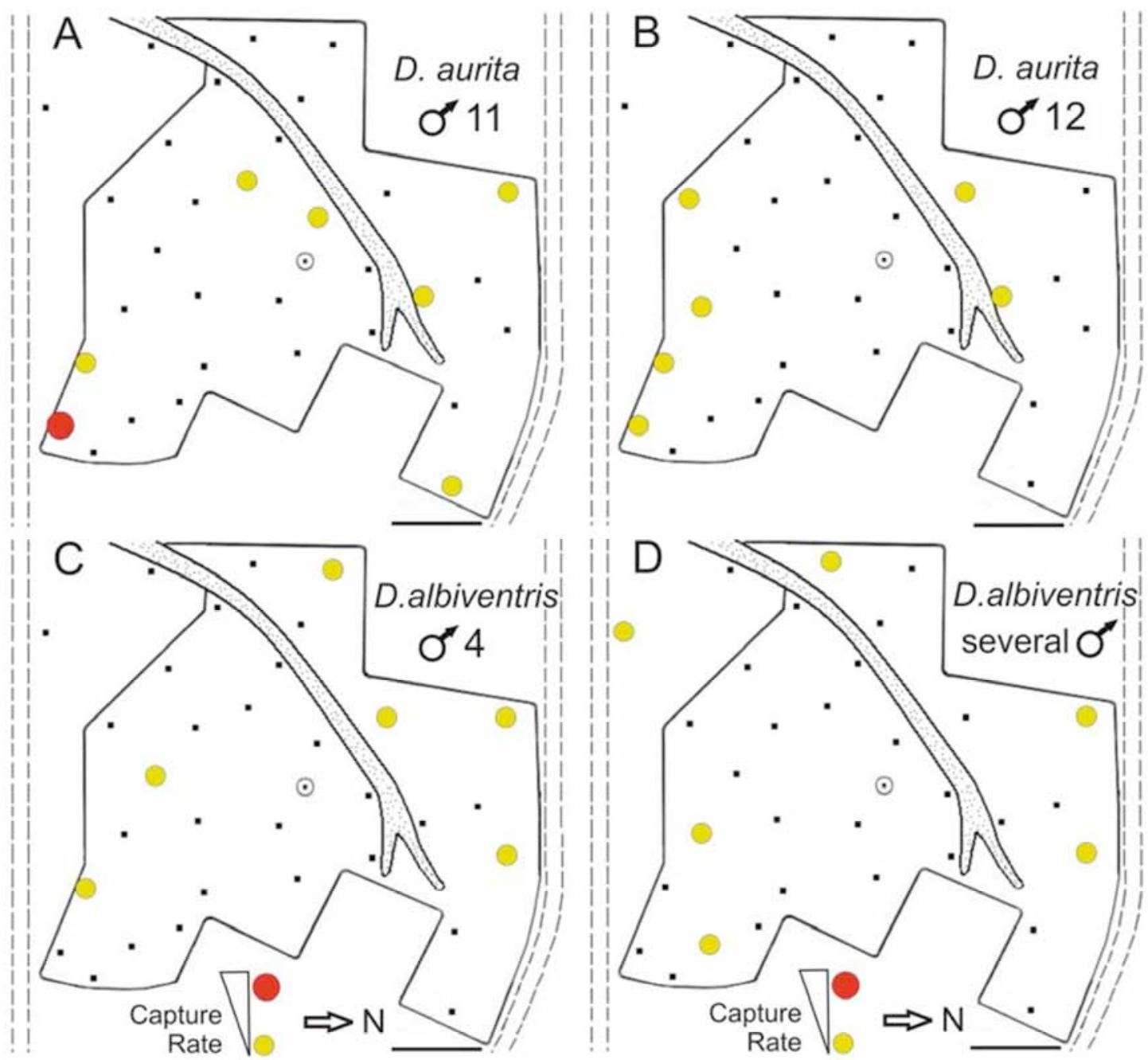

Fig. (4). Capture rates of the more frequent adult males of two sympatric species of Didelphis during the breeding season (July-January) in an Atlantic Forest remnant of southern Brazil. A and B show capture rates of males numbers 11 and 12 of $D$. aurita, with 8 and 6 captures, respectively. $\mathrm{C}$ and $\mathrm{D}$ show capture rates of male 4 (exceptionally captured from May to July) and several D. albiventris males (n $=5$ individuals), with 6 and 6 captures, respectively. Large and red circles refer to traps with more captures (>75\% quartile), and small and yellow circles refer to traps with less captures ( $<25 \%$ quartile) of one individual (except in D). In D, each small and yellow circle refers to the capture of a unique male individual of $D$. albiventris (each one was captured only once). Large dots are non-used live traps, the dotted area is a creek with a stream headwater in the remnant, dashed lines around it are paved roads, the white circle is the remnant centre, and the scale line that covers the entire lower right corner of the remnant measures $53 \mathrm{~m}$.

remnant centre, Didelphis aurita used the interior of the remnant more, while $D$. albiventris used its edges and open areas relatively more.

\section{Captures Regarding the Stream}

For use of space considering all individuals, including young, there was no difference seen for distances of captures between species regarding the closest stream portion in the remnant $(\mathrm{t}=-1.07$, d.f. $=1,36, \mathrm{P}=0.145)$. However, considering only adult individuals of both species, there was a significant difference for captures of $D$. aurita close to the stream compared to the captures of $D$. albiventris $(\mathrm{t}=-2.72$, d.f. $=1,29, \mathrm{P}=0.005)$. This was confirmed by considering only adult females $(\mathrm{t}=-3.49$, d.f. $=1,16, \mathrm{P}=0.002)$, as $D$. aurita females were found closer to the stream (Fig. 3), but not for adult males, who did not select places near the stream $(\mathrm{t}=-0.04$, d.f. $=1,11, \mathrm{P}=0.485)$ (Fig. 4). This difference in the use of space regarding the stream was the same when considering only adult females during the breeding season
(Fig. 3), with D. aurita females showing shorter distances than D. albiventris females $(\mathrm{t}=2.21$, d.f. $=1,14, \mathrm{P}=0.022)$. Also, adult males did not differ between species in the distances from the stream during the breeding season $(\mathrm{t}=$ 0.39 , d.f. $=1,10, \mathrm{P}=0.352$; Fig. 4). The t tests for the nonbreeding season of both sexes were not performed because the number of samples was not sufficient in each case.

Therefore, with regard to the stream inside the remnant, $D$. aurita was captured closer to the stream than $D$. albiventris, and these were most commonly adult females (Table 1). Males did not differ in such distances (Fig. 2B).

\section{Captures Regarding Remnant Edges}

Considering all individuals and also excluding young, there were no differences for distances of captures between species regarding the closest edge of the remnant (with young: $\mathrm{t}=1.32$, d.f. $=1,36, \mathrm{P}=0.097$; without young: $\mathrm{U}=$ $90.00, \mathrm{n}=32, \mathrm{P}=0.078)$. The same results with no 
Table 1. Mean and Standard Deviation of Capture Distances of Didelphis aurita and D. albiventris Regarding to the Remnant Centre Stream, and Edges for all Individuals (Adults, Subadults and Young), Adults, Adult Females and Males, and the Last Ones During the Breeding Season (BS). Number of Individuals used in the Analyses is Shown in Parentheses. Data were not Enough for Analyses During the Non-Reproductive Season

\begin{tabular}{|c|c|c|c|c|c|c|}
\hline Centre of Remnant & All Individuals & Adults & Females & Females in BS & Males & Males in BS \\
\hline \multirow[t]{2}{*}{ D. aurita } & $62.3 \pm 17.9$ & $61.3 \pm 20.3$ & $54.4 \pm 18.1$ & $58.0 \pm 16.4$ & $69.4 \pm 21.5$ & $65.1 \pm 19.0$ \\
\hline & (18) & (16) & $(8)$ & (7) & (8) & (7) \\
\hline \multirow[t]{2}{*}{ D. albiventris } & $69.6 \pm 18.2$ & $75.4 \pm 18.7$ & $76.7 \pm 21.8$ & $77.9 \pm 21.2$ & $72.9 \pm 11.6$ & $74.8 \pm 10.1$ \\
\hline & $(20)$ & (15) & (10) & (8) & (5) & (5) \\
\hline \multicolumn{7}{|l|}{ Stream } \\
\hline \multirow[t]{2}{*}{ D. aurita } & $56.3 \pm 30.4$ & $59.5 \pm 30.8$ & $44.5 \pm 24.7$ & $51.7 \pm 21.8$ & $66.3 \pm 30.1$ & $77.0 \pm 31.6$ \\
\hline & (18) & (16) & (8) & (7) & (8) & (7) \\
\hline \multirow[t]{2}{*}{ D. albiventris } & $81.2 \pm 49.5$ & $96.7 \pm 44.5$ & $107.5 \pm 45.8$ & $103.4 \pm 43.4$ & $75.2 \pm 36.8$ & $68.8 \pm 41.1$ \\
\hline & (20) & (15) & $(10)$ & (8) & (5) & (5) \\
\hline \multicolumn{7}{|l|}{ Edges } \\
\hline \multirow[t]{2}{*}{ D. aurita } & $14.6 \pm 13.5$ & $16.4 \pm 12.5$ & $18.7 \pm 12.6$ & $15.8 \pm 9.8$ & $14.2 \pm 12.8$ & $15.6 \pm 13.1$ \\
\hline & (18) & (16) & (8) & (7) & (8) & (7) \\
\hline \multirow[t]{2}{*}{ D. albiventris } & $7.6 \pm 18.1$ & $6.7 \pm 21.7$ & $4.7 \pm 26.3$ & $0.4 \pm 26.3$ & $10.6 \pm 8.1$ & $10.4 \pm 7.9$ \\
\hline & (20) & (15) & (10) & (8) & (5) & (5) \\
\hline
\end{tabular}

differentiation between species regarding captures and edges were obtained comparing only adult females $(U=26.00$, d.f. $=19, \mathrm{P}=0.060)$, adult males $(\mathrm{t}=0.55$, d.f. $=1,11, \mathrm{P}=$ $0.298)$, females during the breeding season $(\mathrm{U}=21.00, \mathrm{n}=$ $16, \mathrm{P}=0.133$; Fig. 3), and males during the breeding season $(\mathrm{t}=0.78$, d.f. $=1,10, \mathrm{P}=0.224$; Fig. 4); these analyses were performed because the edges were sometimes close to the remnant centre or stream headwater (Fig. 1). Therefore, capture distances from the remnant centre were equal for $D$. albiventris and $D$. aurita females, and the same was seen for males (Table 1, Fig. 2C).

\section{Diet}

Regarding diet, five groups of vertebrates, invertebrates of 11 orders, and 24 species of 14 families of plants (fruits) were found in the diets of the two opossum species (Table 2). In the overall comparison of the relative abundance of feeding items among opossum species, the results were significant for all of the datasets tested $(\mathrm{N}=36$ total individuals) except for vertebrate items, but mainly for females $(\mathrm{N}=21)$ during the breeding season $(\mathrm{N}=23)(\mathrm{P}<$ 0.01); that is, between the two species, females as well as all individuals during the breeding season differed significantly with regard to food consumption. This pattern was seen in the other comparisons made, such as for fruit category (all individuals, $\mathrm{N}=36, \mathrm{P}=0.001$ ), where females differed in their consumption but males did not (Table 3 ). Nine fruit species $(39 \%)$ were found to be consumed by $D$. aurita but not by $D$. albiventris, with differences also occurring in the rates of consumption (Table 2). Overall, there was no difference in the abundance of vertebrate consumption $(\mathrm{N}=$
$36, \mathrm{P}=0.081)$ concerning the animal category, but there was for invertebrates $(\mathrm{N}=36, \mathrm{P}=0.004)$.

Overall, the simplified index of Morisita $(\mathrm{CH})$ revealed a feeding overlap between the two species ranging from 0.2 to 0.5 , but with relatively lower values (that is, more differentiated diets) between females and also during the breeding season (Table 4). As in the analysis of space use and the frequency of consumption of feeding items (which tended to segregate more between females than males in the comparison of species), the indices of feeding overlap for fruits were lower $(\mathrm{CH}=0.19)$ when compared with other food items $(\mathrm{CH}>0.41)$. For fruits, the index was lower between females $(\mathrm{CH}=0.22)$ than between males $(\mathrm{CH}=$ $0.28)$, and was also lower during the breeding season $(\mathrm{CH}=$ $0.17)$ than in the non-breeding season $(\mathrm{CH}=0.25)$. This means that $D$. aurita and $D$. albiventris females segregate more between each other when consuming fruits and particularly during the breeding season.

\section{Time of Activity}

With regard to the time of activity, there was no significant difference in the activity throughout the night between the two species of opossum (Kolmogorov-Smirnov test: $\mathrm{D}=0.429 ; \mathrm{n}=14 \mathrm{D}$. aurita individuals and $7 \mathrm{D}$. albiventris; $\mathrm{P}>0.05$ ) when considering adults and young. The activity of $D$. albiventris varied similarly regarding to the activity of $D$. aurita, although the intensity of use of the remnant area (with more different individuals) was higher for the latter species. The pattern of no differentiation remained, even when considering only adults $(\mathrm{D}=0.400 ; \mathrm{n}=$ 12 and 5; $\mathrm{P}>0.05)$, adult females $(\mathrm{D}=0.233 ; \mathrm{n}=10$ and 3; 
Table 2. Frequencies of Occurrence (in \%) of Food Items Found in Faeces of Didelphis aurita and D. albiventris in a 5-ha Remnant in the Atlantic Forest of Southern Brazil

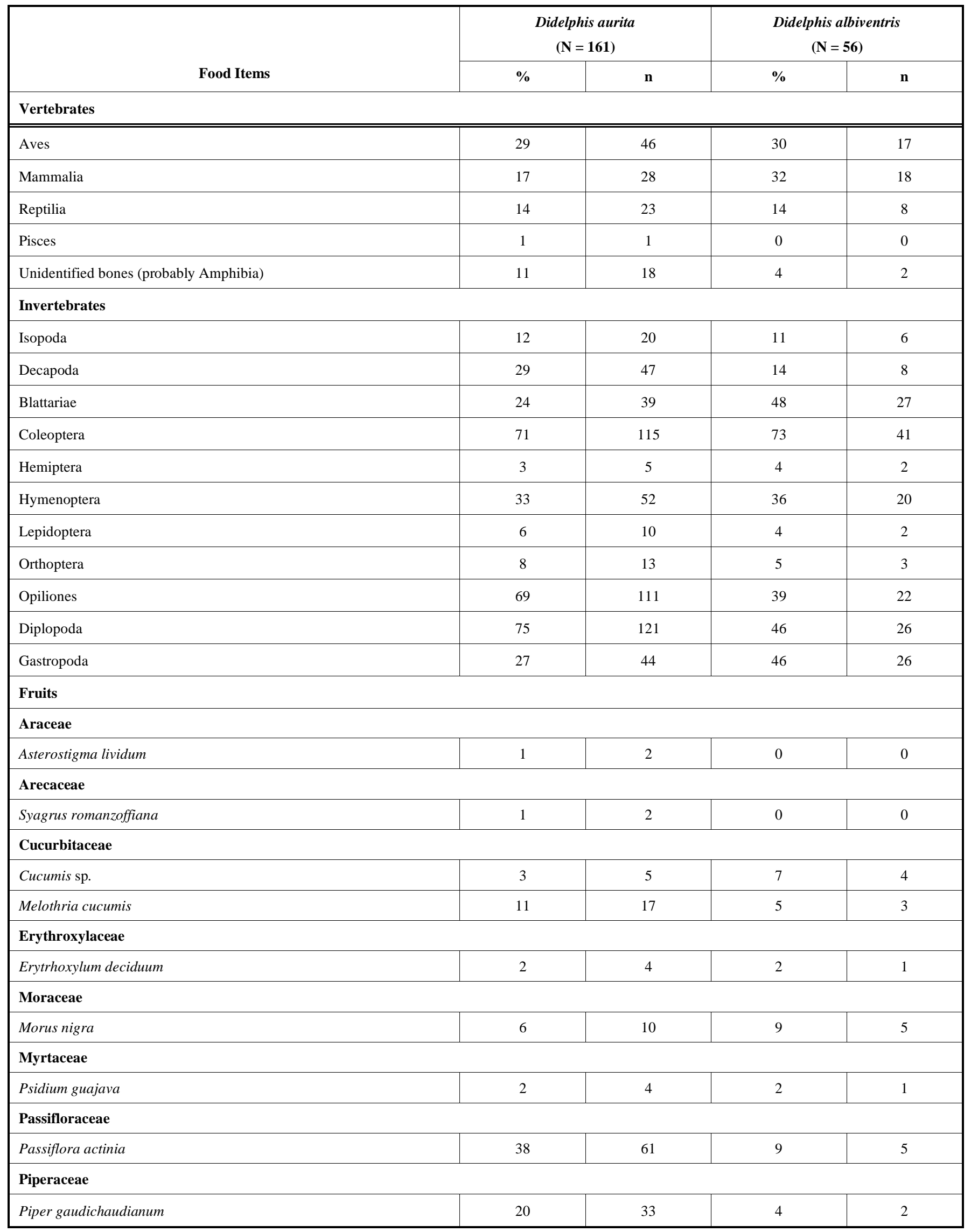


Table 2. contd...

\begin{tabular}{|c|c|c|c|c|}
\hline \multirow[b]{2}{*}{ Food Items } & \multicolumn{2}{|c|}{$\begin{array}{l}\text { Didelphis aurita } \\
\qquad(\mathbf{N}=161)\end{array}$} & \multicolumn{2}{|c|}{$\begin{array}{l}\text { Didelphis albiventris } \\
\qquad(\mathrm{N}=56)\end{array}$} \\
\hline & $\%$ & $\mathbf{n}$ & $\%$ & n \\
\hline \multicolumn{5}{|l|}{ Rhamnaceae } \\
\hline Hovenia dulcis & 2 & 3 & 0 & 0 \\
\hline Rubus rosifolius & 4 & 6 & 4 & 2 \\
\hline Rubus sp. & 2 & 4 & 7 & 4 \\
\hline \multicolumn{5}{|l|}{ Rutaceae } \\
\hline Citrus sp. & 0 & 0 & 2 & 1 \\
\hline \multicolumn{5}{|l|}{ Solanaceae } \\
\hline Cyphomandra corymbiflora & 6 & 9 & 4 & 2 \\
\hline Physalis pubescens & 2 & 3 & 0 & 0 \\
\hline Solanum maioranthum & 1 & 1 & 5 & 3 \\
\hline Solanum granulosoleprosum & 12 & 20 & 2 & 1 \\
\hline Solanum pseudoquina & 1 & 1 & 0 & 0 \\
\hline Solanum sanctaecatharinae & 22 & 36 & 16 & 9 \\
\hline Solanum swartzianum & 6 & 9 & 2 & 1 \\
\hline Unidentified seeds & 2 & 4 & 7 & 4 \\
\hline
\end{tabular}

$\mathrm{N}$ is the total number of faeces used, and $\mathrm{n}$ is the number of faeces a given food appeared.

Table 3. Results of MANOVA Via Randomisation with 1,000 Resamplings, Based on Bray-Curtis Distance, by Comparing the Relative Abundance of Food Items in the Diet Between Two Congeneric and Sympatric Marsupial Species (Didelphis aurita and $D$. albiventris) in an Atlantic Forest Remnant of Southern Brazil

\begin{tabular}{|c|c|c|c|c|}
\hline Items & Factors & Q & Sample Size & P \\
\hline \hline All items & All individuals & 0.78 & $17 / 19$ & $0.002^{* *}$ \\
\hline & Males & 0.43 & $7 / 8$ & $0.019^{*}$ \\
\hline & Females & 0.63 & $10 / 11$ & $0.009^{* *}$ \\
\hline & Breeding season & 0.59 & $12 / 11$ & $0.008^{* *}$ \\
\hline Vertebrates & Non-breeding season & 0.38 & $0.013^{*}$ & 0.081 \\
\hline & All individuals & 0.61 & $17 / 19$ & 0.226 \\
\hline & Males & 0.51 & $7 / 8$ & 0.454 \\
\hline
\end{tabular}


Table 3. contd...

\begin{tabular}{|c|c|c|c|c|}
\hline Items & Factors & Q & Sample Size & $8 / 6$ \\
\hline \hline & Non-breeding season & 0.32 & $17 / 19$ & 0.362 \\
\hline Invertebrates & All individuals & 0.58 & $0.004 * *$ & $0.028^{*}$ \\
\hline & Males & 0.37 & $10 / 11$ & $0.013^{*}$ \\
\hline & Females & 0.44 & $12 / 11$ & $0.015^{*}$ \\
\hline Fruits & Breeding season & 0.29 & $8 / 6$ & $0.031^{*}$ \\
\hline & Non-breeding season & 1.24 & $0.001 * *$ \\
\hline & All individuals & 0.54 & $7 / 8$ & 0.184 \\
\hline & Males & 1.09 & $10 / 11$ & $0.007 * *$ \\
\hline
\end{tabular}

Sample size is the number of sampled individuals of Didelphis aurita and D. albiventris, respectively before and after the bar. Q is the value generated by the test as the sum of the squares. $* \mathrm{P}<0.05, * * \mathrm{P}<0.01$.

Table 4. Index of Feeding Overlap (CH; Simplified Morisita) Between Two Sympatric Species Marsupials (Didelphis aurita and D. albiventris) in an Atlantic Forest Remnant of Southern Brazil. The Lowest Values are in Bold, Meaning More Segregation in Diet

\begin{tabular}{|c|c|c|c|c|c|}
\hline Items & All Individuals & Females & Males & Breeding Season & Non-Breeding Season \\
\hline \hline All food items & 0.42 & 0.35 & 0.39 & 038 & 0.41 \\
\hline Vertebrates & 0.44 & 0.44 & 0.46 & 0.33 & 0.38 \\
\hline Invertebrates & 0.47 & 0.47 & 0.43 & 0.34 & 0.40 \\
\hline Fruits & $\mathbf{0 . 1 9}$ & $\mathbf{0 . 2 2}$ & 0.28 & $\mathbf{0 . 1 7}$ & 0.25 \\
\hline
\end{tabular}

$\mathrm{P}>0.05)$ or females in breeding season $((\mathrm{D}=0.400 ; \mathrm{n}=10$ and $2 ; \mathrm{P}>0.05)$.

\section{DISCUSSION}

The hypothesis that morphologically similar species that coexist in the same region differ according to the main dimensions of niches (Schoener, 1974) was confirmed in this study. With regard to our results, other similar studies involving these sympatric species should confirm our findings. We discuss the relevance of this phenomenon here, by comparing the realised niche of both opossum species in other localities where they do not occur in sympatry, in order to understand whether there is an ecological shift in our study area.

This segregation is thought to be spatial at the beginning, because $D$. aurita occupied the remnant area more frequently and accounted for more recaptures; also, $D$. aurita dominated its interior, becoming the resident species (Cáceres, 2003). This pattern was basically represented by females of both species, which clearly segregated spatially (Fig. 3), unlike males that moved across the study area without any clear spatial segregation (see Davis, 1945). Males, though in a minor number, are thought to have been adequately sampled for these unique populations studied; however, replications by testing other populations are needed. Thus, regarding the remnant centre and stream, its interior was occupied by female $D$. aurita, as the area contains resources thought to be important for this species, such as portions of undisturbed stream with inherent feeding resources (Cáceres, 2003). This behavioural difference regarding sex in the use of space could be related to the promiscuous social system of $D$. aurita (Cáceres and Monteiro-Filho, 2001), in which females are territorial (see also Ryser, 1992), which could eventually occur for $D$. albiventris. These will imply a defence of exclusive richer sites (Ostfeld, 1990), such as the litter invertebrates as food and the vertical stratum for fruits and other resources by $D$. aurita (Cáceres, 2003, Mendel et al., 2008). Both young and adult $D$. aurita are known to explore the vertical stratum of the forest (Cunha and Vieira, 2003), and the same has been reported for D. albiventris (Sanches et al., 2012). Nevertheless, it is expected that $D$. albiventris use the forested habitat in a more horizontal manner (including also open vegetation and forest edges) and $D$. aurita use a more vertical approach, based on their distributional ranges (Cáceres et al., 2007; Emmons and Feer, 1997). This segregation in the use of the vertical habitat is known for sympatric species of Dasyurus in Australia, with some species being more forest dwelling and using the vertical stratum more than others (Dickman, 1987; Jones and Barmuta, 2000). 
The spatial segregation of females of the two Didelphis species could simply be a result of the past competition (and not actual) between such species (see Jones and Barmuta, 2000 , for a similar discussion), but we have concerns about this. Firstly, both species are congeneric and have originated very recently from a common ancestor, exhibiting only $5.7 \%$ of molecular differentiation (Costa and Patton, 2006). That suggests that the species are closely related, and their habits are thought to be similar, as the scansorial movements and the frugivory-omnivory diets (Emmons and Feer, 1997). Moreover, $D$. albiventris female use the interior of remnants regularly when not in sympatry with $D$. aurita (Almeida $e t$ al., 2008; Cáceres et al., 2008; Sanches et al., 2012; Talamoni and Dias, 1999; R.F. Machado, pers. comm.). Didelphis aurita has not been reported to preferentially use stream sites for resources (except for the own study area; Cáceres, 2003). In fact, D. aurita is known to occur in many different environments along its distribution, from the interior and edges of forest fragments to open areas (Cerboncini et al., 2011; Davis, 1945; Mendel et al., 2008; Pires et al., 2002).

Didelphis aurita females have core areas within their home ranges, which are richer in resources, and tend not to be shared with other conspecifics (Cáceres, 2003). Therefore, instead of a simple spatial segregation between species, we postulate that these females will defend their territory not only against their conspecifics, but also against females of $D$. albiventris when in sympatry, since they are similar in size and closely related. Didelphis aurita females exhibit exclusive areas of use that are influenced by food distribution, which is thought to be more important in specific parts of the remnant, like near the stream (e.g. for crabs) and at sites that are rich in Solanaceae, Passifloraceae and Piperaceae fruiting plants (Cáceres, 2003; Cáceres and Monteiro-Filho, 1999; Carvalho et al., 2005). Some parts of the remnant (mostly including edges that are not frequently explored by $D$. albiventris females) were highly used as well, because of the concentration of pioneer plant fruits consumed by D. aurita (Cáceres, 2003; Fig. 3). As a result, there were no differences seen when the use of edges between the two opossum species was compared, besides the fact the edges were sometimes close to the stream headwater (Fig. 1).

Differentiation in diets between the two species was revealed mainly due to the fruit consumption, which is thought to be derived from the spatial segregation between species in the study area. Moreover, such differences were more important for females, and during the breeding season, as expected, since food will be important for lactating females (Julien-Laferrière and Atramentowicz, 1990). On the other hand, $D$. albiventris seems to be capable of surviving in highly urbanised environments, consuming a variety of food items (Cáceres, 2002; Cantor et al., 2010).

Didelphis aurita does not inhabit highly disturbed environments, in contrast to D. albiventris, at least in the Araucaria mixed forest where the species is rather rare (Cáceres et al., 2007). We presume that D. aurita in the Araucaria domain will always depend on forest remnants to survive as a population, even though eventual movement to open areas is needed (Cáceres, 2003; Cerboncini et al., 2011; Pires et al., 2002). In fact, the southern population of $D$. aurita in the Atlantic Forest is thought to be reducing and losing areas for $D$. albiventris due to the high fragmentation level in the region (Cáceres et al., 2007). The potential to colonise urban and disturbed sites by $D$. albiventris is thought to be higher than that for $D$. aurita, provided that the former species is capable of surviving even in central, urbanised areas of Curitiba city (Cáceres, 2000). Moreover, a collected specimen of D. aurita (MHNCI 428) collected and deposited in the Capão da Imbuia Museum of Natural History at Curitiba confirms that $D$. aurita has previously inhabited the now well-urbanised zone of this museum in 1967, but that region (including forest interiors) today is only occupied by D. albiventris (N.C. Cáceres, pers. obs.). The hypothesis of differential habitat requirements between these congeneric species is supported by our results regarding both spatial segregation and diet. If indeed these two species are ecologically segregated by the use of horizontal space (i.e., $D$. albiventris using more grasslands and $D$. aurita more forests, not implying in niche shift), our results could mean more phylogenetic constraints between these two congeneric species than ecological shift, or a mix of both. However, our results, based on the literature, point more to an existence of ecological shift.

Although there is a higher availability of resources for marsupials during the breeding season (Cáceres and Monteiro-Filho, 2001; Gentile et al., 2004; Julien-Laferière and Atramentowicz, 1990), it is thought that D. aurita females more intensely defend the interior or richer sites of a forest remnant (e.g. close to stream; Cáceres, 2003) in this period to protect resources, especially those associated with feeding (Mendel et al., 2008) and shelters (e.g. Hossler et al., 1994), thereby compensating for the increased energy expenditure caused by pregnancy and long lactation. Assuming this behaviour, they visit occasionally forest gaps and edges for fruits of pioneer plants (Cáceres, 2003; Cáceres et al., 1999; Carvalho et al., 2005). During the breeding season, there is a close relationship between the increase in litter biomass of the forest floor, which harbours soil invertebrates, and the population density of $D$. aurita females (Gentile et al., 2004; Mendel et al., 2008), which highlights the importance of such food resources for pregnant and lactating females of the species when living in small forest remnants.

Studies on the sympatric canids Cerdocyon thous (Linnaeus, 1766) and Lycalopex gymnocercus (G. Fischer, 1814), which are two species that are also similar morphologically, have recently revealed that they differ mainly in the period of activity when they live in sympatry in the Araucaria mixed forest, as L. gymnocercus changes its time of activity to avoid meeting with C. thous (Di Bitetti et al., 2009; Vieira and Port, 2007). Marsupials such as Didelphis are more night-dependent for their activities, since they are exclusively nocturnal (Emmons and Feer, 1997), unlike the mentioned canids that are arrhythmic, and can use day or night for activities. This facilitates the adjustment of behavioural strategies of such canids for coexistence in order to avoid competition between them (Di Bitetti et al., 2009). Our data show that there is no differentiation in the pattern of activity between opossum species throughout the night. However, because our sample size is lower for $D$. albiventris in this analysis, the possibility of some differentiation in nocturnal activity between the two species is not rejected. 
However, observing the genus Antechinus in Australia, sympatric species segregate spatially rather than temporally regarding niche dimensions (Dickman, 1986), as is shown here for opossums.

Moreover, the Virginia opossum $D$. virginiana has shown evidence of interspecific competition with the racoon Procyon lotor in North America, which is an example of one species that can significantly shift its space use because the interference of an ecologically, but not phylogenetically similar species (Ginger et al., 2003). If this interaction is plausible, as in Antechinus species, the conflict between congeneric species, such as Didelphis, when living in sympatry is reasonable.

Despite all evidence, we cannot definitively conclude if there is a competition phenomenon actually occurring in such species of Didelphis living in sympatry. Thus, we have evidence of an ecological segregation, and a shift of niche when in sympatry, which is shown by $D$. albiventris occupying more edges and open areas than expected (because the species is also found in forest interiors; e.g. Sanches et al., 2012), and D. aurita more commonly occupying the proximities of stream (also new in the literature) in the remnant interior. However, if the competition hypothesis is true, we believe that in the case of Didelphis females, competition can occur directly, by interference, through aggressive behaviours, sounds, urine and faeces (Burt, 1943), where females of a species will actively chase away the females of other species. Thus, the primary interspecific competition for space use between such females may have led to a reduction of overlap in feeding habitats exhibited by the species according to our data.

South America presents a great diversity of vegetations, which allows the coexistence of many mammalian species in ecotonal areas, some of which are congeneric and morphologically similar (Emmons and Feer, 1997). In this context, $D$. albiventris is related more to open habitats, such as savannahs and grasslands, and D. aurita related more to forest habitats as is the Atlantic Forest (Cáceres et al., 2007; Emmons and Feer, 1997). Currently, D. albiventris and D. aurita distributions meet in the Araucaria mixed forest domain in southern Brazil (Cáceres et al., 2007), which is a region of tension between vegetation types (Leite, 2002), and thus of possible generalised sympatry between these two species (Cáceres et al., 2007). Therefore, we predict that they are not totally syntopic when living in sympatry in the Araucaria domain because of the mentioned mechanisms of ecological segregation in space and diet shown by females.

As the occurrence of grasslands around remnants of natural forest patches in the Araucaria forest is common (IBGE, 1992; Leite, 2002), we believe that the spatial and feeding segregation between these two species would also occur in less disturbed areas of this vegetation type. Although we have no replicates for other populations, we believe that our results are evidence for interspecific competition between these two species of Didelphis, given the morphological, ecological, and phylogenetic proximity of such species, showing an ecological niche shift regarding the natural habits of at least one of the species involved, $D$. albiventris, by being maintained apart from the richest parts of the remnant. Didelphis aurita, on the other hand, is found significantly closer to the remnant centre and stream.
Therefore, we showed that when two similar marsupial species are together in sympatry in the Araucaria forest, there is an ecological shift in at least one of these species, particularly related to sex, season, and resource requirements. We think this is a case of interspecific competition, particularly between females, rather than simply niche segregation (the ghost of competition past), with both species shifting their realised niches in this situation of sympatry.

\section{CONFLICT OF INTEREST}

The authors confirm that this article content has no conflict of interest.

\section{ACKNOWLEDGEMENTS}

We would like to thank Marcelo M. Weber, Geruza L. Melo and two anonymous reviewers for the critical review of the early version of the text, Pró-Reitoria de Pesquisa e PósGraduação at Universidade Federal de Santa Maria for the assistance provided in translating the manuscript (Ed. PróPublicações Internacionais), and Francesco Carotenuto for helping with the figures and insights. NCC is a CNPqresearch fellow in Brazil and currently a research fellow in Italy with resources of $\mathrm{CNPq}$ and Federal University of Santa Maria.

\section{REFERENCES}

Almeida, AJ, Torquetti, CG \&Talamoni, AS (2008) Use of space by neotropical marsupial Didelphis albiventris (Didelphimorphia: Didelphidae) in an urban forest fragment. Revista Brasileira de Zoologia, 25, 214-9.

Ayres, M, Ayres, MJ, Ayres, DL \& Santos, AS (2007) BioEstat 5.0: Aplicações Estatísticas nas Áreas das Ciências Biológicas $e$ Biomédicas, 5nd Ed, Sociedade Civil Mamirauá/CNPq, Belém.

Begon, M, Harper, J\& Townsend, C (2006). In: Begon, M, Harper, J, Townsend, C (Eds) Ecology: from Individuals to Ecosystems, Oxford, Blackwell Scientific Publications 227-65.

Burt, WH (1943) Territoriality and home range concepts as applied to mammals. Journal of Mammalogy, 24, 346-52.

Cáceres, NC (2000) Population ecology and reproduction of the white-eared opossum, Didelphis albiventris (Mammalia, Marsupialia), in an urban environment of southern Brazil. Revista Ciência e Cultura, 52, 171-4.

Cáceres, NC (2002) Food habits and seed dispersal by the white-eared opossum, Didelphis albiventris, in southern Brazil. Studies on Neotropical Fauna and Environment, 37, 97-104.

Cáceres, NC (2003) Use of the space by the opossum DidelphisauritaWiedNewied (Mammalia, Marsupialia) in a mixed forest fragment of southern Brazil. Revista Brasileira de Zoologia, 20, 315-22.

Cáceres, NC, Casella, J, Vargas, CF, Prates, LZ, Tombini, AAM, Goulart, CS \& Lopes, WH (2008) Distribuição geográfica de pequenos mamíferos não voadores nas bacias dos Rios Araguaia e Paraná região centro-sul do Brasil. IheringiaSérie Zoologia, 98, 1-8.

Cáceres, NC, Cherem, J \& Graipel, ME (2007) Distribuição geográfica de mamíferos terrestres na região sul do Brasil. Ciência\&Ambiente, $35,167-80$.

Cáceres, NC, Dittrich, VAO \& Monteiro-Filho, ELA. (1999) Fruit consumption, distance of seed dispersal and germination of Solanaceous plants ingested by the common opossum (Didelphisaurita) in southern Brazil. Rev Ecol Terre Vie 54: 22534.

Cáceres, NC\&Monteiro-Filho, ELA (1998) Population dynamics of the common opossum, Didelphismarsupialis (Mammalia, Marsupialia), in southern Brazil. Mammalian Biology, 63, 169-72.

Cáceres, NC \&Monteiro-Filho, ELA (2001) Food habits, home range and activity of Didelphisaurita (Mammalia, Marsupialia) in a forest fragment of Southern Brazil. Studies on Neotropical Fauna and Environment, 36, 85-92. 
Cáceres, NC, \&Monteiro-Filho, ELA (2007) Germination in seed species ingested by opossums: implications for seed dispersal and forest conservation. Brazilian Archives of Biology and Technology, 50, 921-28.

Cantor, M, Ferreira, LA, Silva, WR \&Setz, EZF (2010) Potential seed dispersal by Didelphis albiventris (Marsupialia, Didelphidae) in highly disturbed environment. Biota Neotropica, 10, 45-51.

Carvalho, FMV, Fernandez, FAS\&Nessimian, JL (2005) Food habits of sympatric opossums coexisting in small Atlantic Forest fragments in Brazil. Mammalian Biology, 70, 366-75.

Catzeflis, F, Richard-Hansen, C, Fournier-Chambrillon, C, Lavergne, A\&Vié, J (1997) Biométrie, reproduction et sympatrie chez Didelphismarsupialiset D. albiventris en Guyanefrançaise (Didelphidae: Marsupialia). Mammalia, 61, 231-44.

Cerboncini, RAS, Passamani, M \& Braga, TV (2011) Use of space by the black-eared opossum Didelphisauritain a rural area in southeastern Brazil. Mammalia, 75, 287-90.

Cerqueira, R. (1985) Distribution of Didelphisin South America (Polyprotodontia, Didelphidae). Journal of Biogeography, 12, 13545.

Connell, JH (1980) Diversity and co-evolution of competitors, or the ghost of competition past. Oikos, 35, 131-8.

Costa, LP (2003) The historical bridge between the Amazon and the Atlantic forest of Brazil: a study of molecular phylogeography with small mammals. Journal of Biogeography 30, 71-86.

Costa, LP, Patton, JL (2006) In: Cáceres, NC, Monteiro-Filho, ELA (Eds) Os marsupiais do Brasil: biologia, ecologia e evolução, Campo Grande, Editora UFMS 321-41.

Davis, DE (1945) The home range of some Brazilian mammals. Journal of Mammalogy, 26, 119-27.

Di Bitetti, MS, Di Blanco, YE, Pereira, JA, Paviolo, A, Pérez, IJ (2009) Time partitioning favours the coexistence of sympatric crab-eating foxes (Cerdocyonthous) and pampas foxes (Lycalopexgymnocercus). Journal of Mammalogy, 90, 479-90.

Dickman, CR (1986) An experimental study of competition between two species Dasyurids. Ecological Monographs, 56, 221-41.

Eisenberg, JF \& Redford, KH. (1999). Mammals of the Neotropics: the central Neotropics. Ecuador, Peru, Bolivia, Brazil. Chicago: University of Chicago Press 609.

Emmons, LH \&Feer, F (1997) Neotropical Rainforest Mammals: a Field Guide, $2^{\text {nd }}$ ed, Chicago, The University of Chicago Press.

Gentile, R \& Fernandez, FAS (1999) Influence of habitat structure on a streamside small mammal community in a Brazilian rural area. Mammalia, 63, 29-40.

Gentile, R, Finotti, R, Rademaker, V \&Cerqueira, S (2004) Population dynamics of four marsupials and its relation to resource production in the Atlantic Forest in southeastern Brazil. Mammalia, 68, 10919.

Ginger, SM, Hellgren, EC, Kasparian, MA, Levesque, LP, Engle, DM\& Leslie, DMJr (2003) Niche shift by Virginia opossum following reduction of a putative competitor, the raccoon. Journal of Mammalogy, 84, 1279-91.

Hossler, RJ, McNinch, JB\& Harder, JD (1994) Maternal denning behaviour and survival of juveniles in opossums in southeastern New York. Journal of Mammalogy, 75, 60-70.

IBGE (1992) Manual Técnico da Vegetação Brasileira, 1st ed, Fundação Instituto Brasileiro de Geografia e Estatística, Rio de Janeiro.

Jones, ME (1998) The function of vigilance in sympatric marsupial carnivores: the eastern quoll and the Tasmanian devil. Animal Behaviour, 56, 1279-84.

Jones, ME\&Barmuta, LA (2000) Niche differentiation among sympatric Australian dasyurid carnivores. Journal of Mammalogy, 81, 43447.
Julien-Laferrière, D\&Atramentowicz, M (1990) Feeding and reproduction of three didelphid marsupials in two neotropical forest (French Guiana). Biotropica, 22, 404-15.

Kaufmann, JH (1974) Habitat use and social organization of nine sympatric species of macropodid marsupials. Journal of Mammalogy, 55, 6680.

Krebs, CJ (1999) Ecological Methodology, $2^{\text {nd }}$ ed, Menlo Park, California.

Leite, PF (2002) Contribuição ao conhecimento fitoecológico do sul do Brasil. Ciência \& Ambiente, 24, 51-73.

Lotka, AJ (1932) The growth of mixed populations: two species competing for a common food supply. Journal of the Washington Academy of Sciences, 22, 461-9.

Maack, R (1981) Geografia física do Estado do Paraná, $2^{\text {nd }}$ ed, Livraria José Olympio, Rio de Janeiro.

Mendel, SM, Vieira, MV, Cerqueira, R (2008) Precipitation, litterfall, and the dynamics of density and biomass in the black-eared opossum, Didelphisaurita. Journal of Mammalogy, 89, 159-67.

Murtaugh, PA (2007) Simplicity and complexity in ecological data analysis. Ecology 88, 56-62.

Ostfeld, RS(1990) The ecology of territoriality in small mammals. Trends in Ecology \& Evolution, 5, 411-5.

Pianka, ER (1978) Evolutionary Ecology, $2^{\text {nd }}$ ed, New York, Harper \& Row.

Pillar, VD (2005) MULTIV, Multivariate Exploratory Analysis, Randomization Testing and Bootstrap Resampling, v. 2.4, Universidade Federal do Rio Grande do Sul, Porto Alegre.

Pillar, VD\&Orlóci, L (1996) On randomization testing in vegetation science: multi factor comparisons of relevé groups. The Journal of Vegetation Science, 7, 585-92.

Pires, AS, Lira, PK, Fernandez,FAS, Schittini, GM\& Oliveira, LC (2002) Frequency of movements of small mammals among Atlantic Coastal Forest fragments in Brazil. Biological Conservation, 108, 229-37.

Rademarker, V\&Cerqueira, R (2006). Variation in the latitudinal reproductive patterns of the genus Didelphis (Didelphimorphia: Didelphidae). Austral Ecology 31, 337-42.

Ryser, J (1992) The mating system and male mating success of the Virginia opossum (Didelphisvirginiana) in Florida. Journal of Zoology, 228, 127-39.

Sanches, VQA, Gomes, MMA, Passos, FC, Graciolli, G \&Ribas, ACA (2012) Home-range and space use by Didelphis albiventris(Lund 1840) (Marsupialia, Didelphidae) in Mutum Island, Paraná river, Brazil. Biota Neotropica, 12, 50-5.

Schoener, TW (1974) Resource partitioning in ecological communities. Science, 185, 27-9.

Talamoni, AS \& Dias, MM (1999) Population and community ecology of small mammals in southeastern Brazil. Mammalia, 63, 167-81.

Tyndale-Biscoe, CH \& Mackenzie, RB (1976) Reproduction in Didelphismarsupialisand D. albiventris in Colombia. Journal of Mammalogy 57, 249-65.

Varejão, JBM \& Valle, CMC (1982) Contribuição ao Estudo da Distribuição Geográfica do Gênero Didelphis (Mammalia: Marsupialia) no Estado de Minas Gerais, Brasil. Lundiana 2, 5-55.

Vieira, EM, Port, D (2007) Niche overlap and resource partitioning between two sympatric fox species in southern Brazil. Journal of Zoology, 27(2), 57-63.

Wootton, JT (1994) The Nature and Consequences of Indirect Effects in Ecological Communities. Annual Review of Ecology and Systematics, 25, 443-66.

Zar, JH(1984)BiostatisticalAnalysis. $2^{\text {nd }}$ ed. Englewood Cliffs: PrenticeHall.

Received: March 09, 2013

Revised: April 16, 2013

Accepted: April 30, 2013

(C) Cáceres and Machado; Licensee Bentham Open.

This is an open access article licensed under the terms of the Creative Commons Attribution Non-Commercial License (http://creativecommons.org/ licenses/by-nc/3.0/), which permits unrestricted, non-commercial use, distribution and reproduction in any medium, provided the work is properly cited. 